Programa de Residência Pedagógica na Licenciatura em Informática: partilhando possibilidades

\title{
DEBATE COMO METODOLOGIA DE ENSINO PARA A APRENDIZAGEM CRÍTICA
}

\author{
Camila L. B. Barbosa ${ }^{1}$, Danillo M. Marinho ${ }^{2}$, Larisse Santos Cabral de O. Carvalho ${ }^{3}$
}

\section{PALAVRAS-CHAVE}

Metodologia de Ensino;

Debate;

Aprendizagem Crítica.

\section{RESUMO}

O trabalho aborda a temática do debate como metodologia de ensino e demonstra a sua importância para os processos de ensino e de aprendizagem. Com a finalidade de desenvolver a formação crítica em sala de aula, com a participação efetiva dos professores, residentes e estudantes de educação básica, numa perspectiva dialógica, o trabalho objetiva apresentar dois estudos de caso em que se desenvolve debate como metodologia para a aprendizagem crítica no IFRN, Campus Ipanguaçu. A descrição dos relatos aponta para o debate como uma metodologia de ensino que contribui para o desenvolvimento dos alunos. A prática dialógica permite o bom aproveitamento intelectual, coletivo e individual dos discentes.

\section{INTRODUÇÃO}

O debate é uma metodologia de ensino que pode proporcionar aos alunos uma formação pautada na construção lógica e na resolução de problemas.

Na perspectiva do pensamento crítico e da comunicação dialógica, o debate é uma metodologia relevante tanto para a formação humana quanto para a formação escolar dos alunos.

A temática evidenciada neste trabalho realça a experiência de estudantes que participam do Programa de Residência Pedagógica (PRP) realizadas por meio do debate como técnica de mediação para o ensino.

Um dos maiores desafios dos professores é encontrar estratégias que estimulem os alunos para participar da aula e para ampliar o seu tempo de estudo.

$O$ debate potencializa a capacidade de reflexão e de construção da argumentação embasada sobre temáticas críticas. O debate como metodologia docente favorece o desenvolvimento dos estudantes com receio de exposição pública, tornando-se assim uma abordagem com importante desdobramento social (UNIVERSIA, 2015).

O objetivo principal do presente artigo é refletir sobre o debate como metodologia facilitadora do processo de ensino para a aprendizagem crítica do

1 Graduando do Curso Superior de Licenciatura em Informática no Instituto Federal de Educação, Ciência e Tecnologia do Rio Grande do Norte (IFRN) - Campus Ipanguaçu. E-mail: camila.b.barbosa@outlook.com

2 Instituto Federal de Educação, Ciência e Tecnologia do Rio Grande do Norte - IFRN, e-mail: danillo_evanescence13@hotmail.com

3 Instituto Federal de Educação, Ciência e Tecnologia do Rio Grande do Norte - IFRN, e-mail: larisse.cabral@ifrn.edu.br 
aluno. Essa metodologia exercita as competências relacionadas à liderança, independência intelectual e à socialização acadêmica e profissional.

No capítulo será apresentado um referencial teórico sobre o tema, bem como, discussão sobre os resultados de experiências vivenciadas por estudantes do Programa de Residência Pedagógica no IFRN, no Campus Ipanguaçu. Os debates aqui apontados foram desenvolvidos em turmas do curso Técnico Subsequente em Manutenção e Suporte em Informática e do curso Técnico Integrado em Informática.

Os resultados demonstram que o debate é uma metodologia de ensino dinâmica e interativa que promove a formação de raciocínio lógico entre outras habilidades. Os grupos que participaram dos debates mediados pelos docentes interagiram mais com o professor, com os colegas e, principalmente, se envolveram mais com os temas escolares abordados.

\section{O CONCEITO DE METODOLOGIA DE ENSINO}

De acordo com Sílvia Maria Manfredi (1993) a origem da palavra metodologia vem do grego e representa a soma da seguinte reunião de ideias: methodos que significa meta (objetivo, finalidade), hodos que significa caminho (intermediação) para alcançar um objetivo e logia que significa conhecimento (estudo).

Metodologia significa o estudo dos métodos para atingir caminhos e alcançar metas, objetivo ou finalidade. A concepção de metodologia do ensino corresponde ao estudo de variadas trajetórias traçadas, planejadas e vivenciadas pelos profissionais da educação para orientar e mediar o processo de ensino em função de objetivos ou fins educativos.

A metodologia de ensino é a parte da pedagogia que se envolve de forma direta com a organização e o controle da aprendizagem dos alunos.

De acordo com Ilma Veiga, "as técnicas devem ser compreendidas como componentes de estratégia geral de abordagem do fenômeno educativo (...), como um instrumento teórico e prático(...) (VEIGA, 1991, p.25 apud VASCONCELOS,1988, p.99).

Os métodos e as técnicas cumprem uma função importantíssima para o processo educativo e devem ser conhecidas teoricamente para o pleno potencial prático no âmbito escolar.

De acordo com Libâneo (2013), o conceito mais simples de metodologia é o caminho para atingir um determinado objetivo por meio de meios adequados para realizar os mesmos, em relação à educação, objetivo e conteúdo.

As metodologias de ensino estão sempre atreladas aos objetivos da aula, sofisticando o planejamento e a sistematização dos planos das ações.

Para Veiga (2006), as metodologias de ensino estão sujeitas a alcançar o objetivo do docente por meio do aprimoramento das técnicas utilizadas em sala de aula e, ainda, incorporando a tecnologia a este processo.

Com base nas contribuições de Nérice (1987) argumentamos que tratar os métodos de ensino como um conjunto de procedimentos lógico e psicologicamente 
ordenados conduzem o estudante para desenvolver suas habilidades, atitudes e pensamento. São possibilidades de metodologia de grupo: painéis, simpósios, debates, discussões, entre outros (NÉRICE, 1987).

\section{DEBATE COMO METODOLOGIA DE ENSINO}

A provável origem etimológica da palavra debater é do francês débattre, que vem do latim debattuere, significando disputar, alterar e brigar (VEIGA, 1991).

Para o ensino, o debate é um recurso eficaz pois permite o confronto de diferentes pontos de vistas entre os interlocutores (estudantes e professores). Antes do debate é necessário que os alunos acessem informações sobre o seu conteúdo.

Cabe ao professor mediar a discussão de forma sucinta. "Viver cada aula como uma hipótese a ser testada. No debate entre professor e aluno cada um está exposto ao outro e ninguém pode dizer como terminará a aventura" (GUSDORF 1987, p. 143).

A metodologia do debate acontece de forma integralmente mediada pelo professor uma vez que todo o grupo deverá ser bem orientado para a sua realização. Para fundamentar as argumentações, é fundamental uma leitura atenciosa sobre o tema do debate.

Um importante indicador para saber se o aluno realmente construiu e incorporou o conhecimento de forma reflexiva é perceber a sua capacidade de explicar um conteúdo com suas próprias palavras, de preferência, intercalando tal conteúdo com conhecimentos prévios sobre o assunto a ser debatido.

No debate também é desejável que os alunos exercitem a imaginação. Sobre isso, é recomendado que o professor proponha desafios intelectuais trazendo comparações e sobretudo que se aprenda a respeitar a diversidade de opinião: "a criatividade é alimentada por informações. A probreza de ideias faz definhar e limita o crescimento da criatividade" (SHIPLEY, 1969, p. 157).

O debater ajuda a abrir novas perspectivas para que o aluno possa expor suas opiniões sobre o tema, progredindo o fluxo do pensamento. O diálogo vai abrir o campo subjetivo porque aprimora uma pluralidade de pontos de vistas.

\section{POR QUE DEBATER E COMO DEBATER EM SALA DE AULA?}

Um bom debate faz com que os estudantes exercitem sua capacidade de liderança e também busquem independência intelectual (porém, observa-se que nunca ele deve ser usado para a subordinação). Sabe-se que o debate não é uma atividade fácil, pois a turma deve se sentir livre e a vontade para expressar suas ideias de forma espontânea e o professor deve se empenhar em estimular os alunos a essa independência sem opor sua forma de argumentar sobre o assunto exposto para o debate.

Como aponta Snyders (1974) é preciso que o professor firme uma posição e ao mesmo tempo incite os alunos a apresentarem cada vez mais questões. Com isso, nunca haverá um empobrecimento da própria reflexão de maneira significativa. 
Mas, como podemos inserir essa técnica de debate no ambiente escolar? Essa questão é muito importante, pois ao utilizarmos esse método devemos ter conhecimento sobre ele. Então, primeiramente os estudantes devem estar apropriados sobre o tema com estudos individuais, pesquisas e outras atividades que possam ampliar o número de informações acerca do tema.

Uma prática eficaz é que: 1) o professor ou estudante seja o moderador da discussão para que haja um equilibrio e organização da atividade; depois de todos expuserem suas opiniões e, consequentemente, discutirem entre si o assunto debatido deve ocorrer a participação em conjunto ao final da aula; 3) por fim, o professor deverá fazer uma análise crítica de tudo que foi exposto, fazendo um balanço geral com apontamentos reflexivos sobre os comportamentos intelectuais e emocionais de todos os envolvidos; cabe ainda um segundo momento para amadurecer as ideias já estabelecidas.

As técnicas de debate não garantirão grandes resultados se houver um distancimento entre os estudantes e professor. Desta forma, eles devem enxergar o educador como alguém muito especial e maduro para eles.

Diante disso, é preciso saber muito bem do assunto, ver as dificuldades de cada um e tentar sempre entusiasmar os alunos para o debate a ser feito, fazendo elogios sinceros e dando dicas construtivas, além de desenvolver sentimentos de êxito, auto-realização e auto-afirmação.

Para finalizar, não se pode esquecer de forma alguma de proporcionar um feedback para todos, assim realizando uma avaliação coletiva e individual.

\section{RECOMENDAÇÕES PRÁTICAS PARA A DISCUSSÃO E O DEBATE}

A prática do debate é uma sugestão para intervir nos processos de ensino e aprendizagem de modo significativo, auxiliando o aluno tanto a desenvolver a compreensão crítica, deixando o senso comum de lado, como também abrangendo novas concepções sobre um tema específico em sala de aula.

Para que um debate aconteça existem inúmeras regras para a utilização da técnica que visa ativar os processos mentais de cada um. Sabe-se que a democracia é o ponto chave para se ter um trabalho mais competente, fazendo com que as recomendações para essa prática seja cada vez mais bem compreendidas.

Segundo Lefèbvre (1975) e Robert Henry (1915), para a preparação do debate deve obedecer a alguns pontos, a saber:

- Organizar a sala para o debate para que cada um veja todos os integrantes;

- Não levar o debate para o lado competitivo, mas para o trabalho em equipe, analisando a contribuição de cada um;

- Estudar o assunto a ser discutido para se ter conhecimento ao debater;

- Os grupos devem reunir evidências e exemplos que servirão de suporte para sua argumentação; 
- Os grupos devem organizar uma ordem de fala entre seus integrantes;

- A opinião do aluno deve ser respeitada e não é possível apontar quem está certo ou errado;

- Durante a discussão analisar cada grupo e o comportamento de cada um fazendo grupo-análise;

- $\quad$ Não esquecer que muitas vezes os desacordos têm caráter emocional;

- $\quad$ Ser objetivo em sua fala e ser coerente com sua argumentação;

- Não fugir do tema a ser debatido;

- Aprender a elogiar. O eleogio estimula o companheiro a prosseguir a motivar o outro;

- É importante estipular o tempo para cada participante para expor suas opiniões e argumentar, contra-argumentar ou para réplica e tréplica;

- $\quad$ E depois que a discussão for feita, o professor deve fazer uma avaliação da atividade junto com os alunos e destacar o que não foi abordado.

É conveniente que, antes do debate ocorrer, vê-se como relevante ter uma aula preparatória para que os alunos saibam das regras do debate, como conduzi-lo, contextualizando e levantando os conhecimentos prévios de cada um.

Outro ponto importante que pode ser citado sobre as recomendações para um debate acontecer é, sempre que necessário, estabelecer estratégias para fomentar outra discussão caso a primeira se apresente inconclusiva ou que não dê subsídios às falas de cada um que esteja presente. Isso faz com que a aplicação do método fique mais eloquente e satisfatório.

\section{METODOLOGIA}

Em relação ao conhecimento prático para embasar nosso trabalho, relatando assim as experiências vivenciadas em âmbito educacional, o método utilizado foi o estudo de caso, que, de acordo com Gil (2008), consiste em permitir o conhecimento mais amplo e detalhado do que foi vivido:

\footnotetext{
"O estudo de caso é caracterizado pelo estudo profundo e exaustivo de um ou de poucos objetos, de maneira a permitir o seu conhecimento amplo e detalhado, tarefa praticamente impossível mediante os outros tipos de delineamentos considerados. (GIL, 2008, pgs. 57-58)"
}

Assim sendo, esse método de pesquisa foi fundamental para descrever de maneira clara e sucinta o que foi vivenciado no contexto do uso do debate no ambiente escolar, explorando situações reais como o tema da "obsolescência programada", que nos traz questionamentos do uso excessivo das tecnologias e os impactos que ela pode acarretar, e também o tema da "definição do humano: impactos das tecnologias", trazendo questões sociais, filosóficas e econômicas da sociedade. 


\section{ESTUDO DE CASO: EXPERIÊNCIAS COM O DEBATE NO PROGRAMA RESIDÊNCIA PEDAGÓGICA}

A estrutura de um debate formal envolve três grupos distintos: aqueles que defendem uma resolução de um problema previamente levantado; aqueles que se opõem à resolução apresentada; e aqueles que deverão julgar a qualidade das evidências apresentadas e as argumentações das duas partes (OLIVEIRA, 2010?).

Sempre em toda discussão é necessário entrar em um acordo para a resolução de um tema problema, assim o debate tem um viés mais significativo e mais relevante.

É uma caracterização abrangente para designar uma diversidade de pesquisas que coletam e registram dados de um caso particular ou de vários casos a fim de organizar um relatório ordenado e crítico de uma experiência, ou avaliá-la analiticamente, objetivando tomar decisões a seu respeito ou propor uma ação transformadora. (CHIZZOTTI, 1995, pg 102).

A transcrição e a análise do debate permitiu verificar como esse método de ensino foi utilizado primeiramente na disciplina de "Manutenção Avançada de Computadores" na turma do curso Técnico Subsequente em Manutenção e Suporte em Informática e com a disciplina "Organização e Manutenção de Computadores" na turma do curso Técnico Integrado em Informática no IFRN - Campus Ipanguaçu no turno vespertino, com o professor orientador do programa residência pedagógica.

A aplicação do debate como método de ensino foi estabelecida por meio da realização de práticas envolvendo as turmas já citadas acima. Inicialmente, foi promovida a exibição de um vídeo como forma de dar subsídios aos estudantes para o debate. Estes vídeos abordam em seu conteúdo informações e/ou reflexões sobre o tema proposto. Foram utilizados os espaços das salas de aula dos estudantes para a exibição do material, recorrendo ao datashow, computador e caixas de som como recursos audiovisuais.

Em seguida, os debates em si foram realizados, ocorrendo em espaços distintos aos da sala de aula. Nos casos em relato, recorreu-se à sala de reuniões e ao auditório do IFRN - Campus Ipanguaçu.

Em cada ambiente foi pensado uma organização e posicionamento dos participantes, de modo a criar grupos com posicionamentos distintos sobre o tema, com localização bem delimitada no espaço. Assim, na sala de reuniões pensou-se em posicionar grupos com visão contra e a favor sobre o tema; já no auditório, organizou-se o espaço com grupos contra e a favor, mas também um terceiro grupo representando a plateia do debate.

A terceira prática (realizada com uma turma de ensino médio integrado) lizado com a turma do integrado de informática, promoveu-se a simulação de uma Assembléia Geral das Nações Unidas. Neste caso, cada estudante representava um país, cabendo por parte de cada um deles a ornamentação e caracterização conforme cultura e tradição da nação que representara. 


\section{ESTUDO DE CASO DA TURMA TÉCNICO SUBSEQUENTE EM MANUTENÇÃO E SUPORTE EM INFORMÁTICA}

O primeiro tema escolhido para o debate foi "Obsolescência Programada" e teve como pressuposto um documentário ${ }^{4}$ referente ao assunto exibido em sala de aula pelo docente.

Sabe-se que obsolescência programada é uma técnica utilizada por fabricantes para forçar a compra de novos produtos, mesmo que os que cada pessoa já tenha esteja em perfeitas condições de funcionamento. Esta ideia consiste na produção de bens já estabelecendo o término da vida útil deles. Isso gera grande impacto na vida das pessoas, pois o excessivo consumo e descarte de produtos eletrônicos vem degradando principalmente o meio ambiente, gerando o lixo eletrônico que é tão prejudicial aos seres vivos.

Com o objetivo de conscientizar os estudantes a terem um pensamento crítico e reflexivo sobre o impacto das tecnologias, foram realizadas duas discussões com a turma em dois ambientes distintos do IFRN - Campus Ipanguaçu (sala de reuniões e auditório), a fim de quebrar a rotina da sala de aula.

A turna foi dividida em três grupos: um a favor da obsolescência programada, personificada em uma empresa hipotética que defendia o tema; um grupo contra que não defendia obsolescência; e a plateia, constituída por empresários que iriam escolher o grupo com o argumento que mais os convencessem.

O professor da disciplina conduziu todo o debate, apresentando inicialmente uma contextualização do tema a fim de que os estudantes pudessem ter mais subsídios e mais familiaridade com o assunto, diminuindo assim a tensão da realização da atividade. Cada grupo tinha o direito de fazer uma pergunta por vez, com direito a replica e treplica e a plateia podia intervir caso considerassem necessário.

Como os grupos tinham vários componentes, cada integrante tinha o direito de fazer uma pergunta, incentivando e garantindo assim a participação de todos no debate. Ainda, caso já tivesse realizado alguma intervenção no debate, o componente também não poderia responder perguntas dirigidas ao grupo. Com esse mesmo intuito de participação, cada componente tinha um tempo de no máximo de cinco minutos de duração.

Como o tema é uma problemática bastante relevante para os alunos que serão futuros técnicos de manutenção de computadores, foi necessário realizar uma segunda discussão para finalizar o debate. Os licenciandos do programa Residência Pedagógica que atuaram na atividade tiveram um papel importante nesses debates, onde cada um ficou responsável por um grupo (um a favor, outro contra), bem como o próprio professor da disciplina, o qual apoiou o grupo da plateia. Cada um auxiliou seu grupo, no sentido de auxiliar na construção das perguntas, ajudando-os

\footnotetext{
${ }^{4}$ A conspiração da lâmpada, está disponível na plataforma do Youtube no canal consciência universal
} 
a como proceder frente a um debate, observando o andamento da discussão e também na oralidade.

Com essa atividade prática, foi possível observar que os alunos no início tinham receio de se pronunciar no contexto de um debate formal, pois muitos não tinham o costume de falar em público, por terem vergonha ou nunca ter participado de uma atividade que envolvesse uma discussão de um tema tão problemático.

Já no segundo momento de debate percebeu-se uma diferença bastante consideravél, pois os alunos estavem menos tensos, mais motivados para falar do tema e com subsídios suficentes para argumentar.

\section{ESTUDO DE CASO DA TURMA TÉCNICO INTEGRADO EM INFORMÁTICA}

Ao lançar a proposta da realização do debate com a turma do curso técnico integrado em Informática, o professor percebeu uma boa aceitação por parte dos estudantes dessa prática. Assim, a experiência realizada com a turma do Técnico Subsequente em Manutenção e Suporte em Informática foi repetida, promovendo alguns ajustes.

O tema escolhido foi a definição do humano: impactos da tecnologia que teve como referência uma palestra em um canal do youtube com o palestrante o físico Luiz Alberto Oliveira5, que trata sobre questões filosóficas e sociológicas sobre o comportamento do ser humano diante das tecnologias e suas consequências em cada país.

Um dos ajustes realizados para esse debate foi em relação a configuração da turma, haja vista que não houve divisão em grupos, sendo realizada uma simulação de uma assembleia da Organização das Nações Unidas (ONU), onde cada estudante representava um país.

O debate ocorreu na sala de reuniões da instituição, cada assento era destinado a um membro de um país, fazendo o uso de placas de identificação na mesa. Além disso, cada estudante deveria estar caracterizado formalmente, de acordo com a cultura de cada país que representara. Em soma, os licenciandos residentes criaram crachás para cada membro desta assembleia.

Cada residente desempenhou um papel na condução do debate, tendo como papel representar observadores de organismos internacionais: um ficou responsável por representar Organização Mundial da Saúde - OMS da Indonésia; outro seria observador da Organização Mundial do Trabalho - OMT, da Itália; e um terceiro residente seria observador da Organização das Nações Unidas para a Educação, a Ciência e a Cultura - UNESCO, da Índia. Tinha também o secretariado geral da ONU constituído por três membros influentes que possuíam um papel importante de conduzir a discussão.

\footnotetext{
5 "A definição do humano: impactos da tecnologia". Link do vídeo no Youtube: https://www.youtube.com/watch?v=9NZHAcJ1tnI
} 
Cada membro dos países representado no debate tinha o direito de direcionar uma pergunta por vez a um outro representante, com direito a réplicas caso ele não se sentisse satisfeito com a resposta dada.

De forma geral, a discussão foi bastante produtiva, observando muita interação e participação dos estudantes, os quais se empenharam muito. Cada representante de cada país teve a preocupação de pesquisar sobre a nação que estava representado, por exemplo a situação econômica e social, a ponto de incorporarem a sua cultura. Cabe o registro de que alguns estudantes encenaram um personagem, mudando seu comportamento, interpretando a língua do país representante, demonstrando-se assim muito dinâmicos ao incorporarem seus respectivos chefes de Estado.

Mais uma vez, esse método de ensino mostrou-se viável para explorar o lado criativo dos estudantes diante de questões problemáticas e foi de grande importância para o aprendizado deles, estimulando-os. Com isso, a prática foi concluída após uma análise de que esse método é bem eficaz cognitivamente, ajudando a cada um deles a fixar o conteúdo com maior precisão.

\section{CONSIDERAÇÕES FINAIS}

O relato registrado neste artigo se propôs a compreender de forma clara como o debate pode ter grande contribuição para os processos de ensino e de aprendizagem das turmas que os bolsistas do programa de Residência Pedagógica ministraram aula, com o acompanhamento do professor, possibilitando entender o aplicação deste método na prática.

Consideravelmente, notou-se que os estudantes foram bem receptivos a essa abordagem, observando nitidamente a grande evolução que eles tiveram, na medida do processo de desenvolvimento do debate, da preparação até a hora da sua execução, refletindo que este fato foi muito importante para o seu crescimento como estudantes e, para além disto, como pessoas que aprenderam a arte de socializar, analisar e respeitar as opiniões de cada um que participou das discussões.

Portanto, os métodos de ensino não devem ser compreendidos superficialmente a partir de leituras descontextualizadas, pois cada método procura promover aos educandos a apropriação do conhecimento necessário ao assunto a ser ministrado em sala e, no caso do debate, seria indispensável essa apropriação, uma vez que se deve saber como aplicá-lo, trazendo uma perspectiva significativa para o aprendizado.

A realização de debates em sala de aula oferece aos alunos a oportunidade de exporem suas ideias prévias a respeito de fenômenos e conceitos científicos num ambiente estimulante. Torna-se, então, necessária a criação de espaços onde os alunos possam falar e, por meio da fala, tomar consciência de suas próprias ideias, além de aprenderem a se comunicar com base num novo gênero discursivo: o científico escolar (CAPECCHI; CARVALHO, 2000). 
Fica claro que o planejamento de um debate é fundamentalmente essencial para o seu desenvolvimento adequado, da mesma forma que para qualquer atividade pedagógica, devendo levar em consideração desde as estratégias de sensibilização e de escolha do tema, os materiais de apoio como textos, vídeos, a forma de registro das ideias discutidas, até a avaliação dos alunos. E isso foi feito e realizado com muito empenho e rendeu resultados positivos.

Por fim, se espera que o debate seja inserido sempre que for necessário nas salas de aulas, já que é um método assertivo que foi verificado nos estudos de caso descritos neste trabalho. Ainda, a adoção do debate como método de ensino por parte dos docentes pode ser estratégia de disseminação do conhecimento, tendo

como consequência o afetamento positivo da vida de cada estudante, em distintos aspectos: acadêmico, cotidiano e profissional.

\section{REFERÊNCIAS}

CARVALHO, A. M. P.; GIL-PEREZ, D. O saber e o saber fazer do professor. In: CASTRO, A.D.; CARVALHO, A.M.P. Ensinar a ensinar. São Paulo: Pioneira, 2001.

CHIZZOTI, A. Pesquise em ciências humanas e sociais. São Paulo: Cortez, 1995.

GIL, Antonio Carlos. Métodos e Técnicas de Pesquisa Social. 6. ed. São Paulo: Atlas, 2008.

GUSDORF, G. Professores para quê? São Paulo, Martins Fontes, 1987.

LEFÈBVRE, H. Lógica formal/lógica dialética. Rio de Janeiro: Civilização Brasileira, 1975.

LIBÂNEO, J. C. Didática. 2. ed. São Paulo: Cortez, 2013.

MANFREDI, S. M. Metodologia de ensino: diferentes concepções (versão preliminar). 1993. Disponível em:

<http://www.formar.fe.unicamp.br/sites/www.formar.fe.unicamp.br/files/metod ologia-do-ensino-diferentes-concepcoe-s.doc.>. Acesso em: 30 out. 2019.

NÉRICE, I. G. Didática geral dinâmica. 10 ed., São Paulo: Atlas, 1987.

OLIVEIRA, Lucas. Como organizar um debate formal em sala de aula. Site Canal do Educador. [2010?]. Disponível em:

<https://educador.brasilescola.uol.com.br/estrategias-ensino/como-organizarconduzir-um-debate-formal-sala-aula.htm>. Acesso em: 15 nov. 2019.

ROBERT, H. M. Regras de Ordem de Robert. Tradução, Randyl Kent Plampin. New York: New York, 1915. 
SHIPLEY, C. M. et. al. Síntese de métodos didáticos. Porto Alegre, Globo, 1969.

SNYDERS, G. Para onde vão as pedagogias não diretivas? Lisboa: Moraes, 1976.

UNIVERSIA. Professor: veja motivos para estimular o debate em sala de aula. Site Universia - Notícias Educação. 17 de junho de 2015. 2015. Disponível em:

https://noticias.universia.com.br/educacao/noticia/2015/06/17/1126897/professo r-veja-motivos-estimular-debate-sala-aula.html. Acesso em 15 nov. 2019.

VASCONCELOS, I. A metodologia enquanto ato político da prática educativa. In: CANDAU, V. M. (org.). Rumo a uma nova didática. Petrópolis, Vozes, 1988.

VEIGA, I. P. A. Técnicas de ensino: Por que não? 18. ed. São Paulo: Papirus, 1991. VEIGA, I. P. A. Técnicas de ensino: novos tempos, novas configurações. Papirus, 2006. 